\title{
Efficacy and Safety of Misoprostol for Prevention of Post-Partum Haemorrhage: A Comparative Study
}

\author{
Selina Akter ${ }^{1}$, Md. Shahadat Hossain Khan ${ }^{2}$, Kashifa Khatun ${ }^{3}$, Shamsun Nahar ${ }^{4}$, Shimul Akter ${ }^{5}$ \\ ${ }^{1}$ Senior Consultant, Department of Obstetrics \& Gynaecology, Central Police Hospital, Rajarbag, Dhaka, Bangladesh; \\ ${ }^{2}$ Assistant Professor, Department of Pediatrics, Shaheed Suhrawardy Medical College, Dhaka, Bangladesh; \\ ${ }^{3}$ Associate Professor, Department of Gynaecology \& Obstetrics, National Institute of Cancer Research Hospital, \\ Dhaka, Bangladesh; ${ }^{4}$ Assistant Professor, Department of Gynaecology \& Obstetrics, Abdul Malek Ukil \\ Medical College, Noakhali, Bangladesh; ${ }^{5}$ Associate Professor, Department of Gynaecology \& Obstetrics, \\ Monowara Sikder Medical College, Shariatepur, Bangladesh
}

[Received on: 22 April 2021; Accepted on: 12 May 2021; Published: 1 July 2021]

\begin{abstract}
Background: Post-partum haemorrhage condition is a serious condition after delivery. Objective: The purpose of the present study was to see the efficacy and safety of misoprostol for the prevention of post-partum haemorrhage. Methodology: This analytic cross-sectional study was carried out in the Department of Gynaecology and Obstetrics at Mymensingh Medical College Hospital (MMCH), Mymensingh, Bangladesh from January 2006 to June 2006 for a period of six months. Pregnant women who were admitted in $\mathrm{MMCH}$ during the above period and were expected to have vaginal delivery and women at term with singleton pregnancy were included as study population. Women were divided into 2 groups. Women were in the group A who were treated with misoprostol and women who were treated with oxytocin were in group B. Blood loss during delivery was estimated subjectively by the attending obstetrician. Results: A total number of 100 women were recruited for this study of which 50 women were in the group A and the rest of 50 women were in group B. In this study majority of the patients were belonged to age group 20 to 25 years in both the groups. In oxytocin group $2.0 \%$ have developed nausea, $4.0 \%$ patients have developed shivering. None have developed vomiting, diarrhoea, temperature. In misoprostol group 10.0\% patients have developed nausea, $18.0 \%$ patients have developed shivering, $4.0 \%$ patients have developed rise of temperature, none have developed diarrhoea, vomiting. The differences were statistically significant. In this study $4.0 \%$ patients from oxytocin group and $2.0 \%$ patient from misoprostol group required blood transfusion. Conclusion: In conclusion less amount of blood loss is found in misoprostol group than oxytocin group. [Journal of National Institute of Neurosciences Bangladesh, July 2021;7(2):xx-xx] [Journal of National Institute of Neurosciences Bangladesh, July 2021;7(2):152-155]
\end{abstract}

\section{Keywords: Efficacy and Safety; Misoprostol; Prevention; Post-Partum Haemorrhage}

Correspondence: Dr. Selina Akter, Senior Consultant, Department Of Obstetrics \& Gynaecology, Central Police Hospital, Rajarbag, Dhaka, Bangladesh; Email: drselinaakter1122@gmail.com; Cell no.: +8801726050401

Conflict of interest: There is no conflict of interest relevant to this paper to disclose.

Funding agency: This research project was not funded by any group or any institution.

Contribution to authors: Akter S, Khan MSH, Khatun K were involved in protocol preparation, data collection and literature search and manuscript writing. Nahar S, Akter S were involved in preparation and revision of this manuscript.

How to cite this article: Akter S, Khan MSH, Khatun K, Nahar S, Akter S. Efficacy and Safety of Misoprostol for Prevention of Post-Partum Haemorrhage: A Comparative Study. J Natl Inst Neurosci Bangladesh, 2021;7(2): 152-155

Copyright: (C2021. Akter et al. Published by Journal of National Institute of Neurosciences Bangladesh. This article is published under the Creative Commons CC BY-NC License (https://creativecommons.org/licenses/by-nc/4.0/). This license permits use, distribution and reproduction in any medium, provided the original work is properly cited, and is not used for commercial purposes.

\section{Introduction}

Postpartum hemorrhage is the leading cause of maternal death in the developing world and it is accounting for $14.9 \%$ of such death in areas and less than $10.0 \%$ in advanced countries ${ }^{1}$. The importance of prevention, particularly where there is limited access to emergency medical facilities is therefore obvious. The WHO has recommended the use of intramuscular prophylactic administration of oxytocin in the third stage of labour ${ }^{2}$, which is now routinely used in many countries as well as in Bangladesh ${ }^{3}$. Ergometrine has also been used as an oxytocic but is associated with side effects and contraindicated in hypertension, cardiac disease, Rh (-ve) mother and pre eclampsia ${ }^{4}$. Potential problems with the use of ergometrine and oxytocin in developing countries especially in rural areas include the need of protection 
from light and for refrigeration because oxytocic agents are not stable at high ambient temperature, they require special storage condition as well as needles and syringes for administration ${ }^{5}$. Someone is needed to inject this drugs to the patients, such trained personal are not always available particularly in the rural areas.

Misoprostol is a prostaglandin E analogue and it is a potent uterotonic agent ${ }^{6}$. It has gastric antisecretory properties and has clinical application in peptic ulcer, induction of abortions, cervical priming and induction of labour. Absorption of misoprostol is very rapid, being detected in circulation within 2 minutes of its introduction ${ }^{7}$. Potential advantages of misoprostol includes its stability in light and at room temperature, its low cost and easy administration can be given orally or rectally, as well as less side-effects; furthermore, it does not increase the blood pressure ${ }^{8}$. Its' safety has been established in studies over the past 10 year for the prevention and management of peptic ulcer?

In this study rectal administration of misoprostol had been studied as an alternative to oxytocin for the prevention of $\mathrm{PPH}$. The purpose was not to replace conventional use of oxytocin but to make misoprostol available to midwives and rurally located physicians for whom parenteral oxytocin seems to be either impractical or unavailable.

\section{Methodology}

Study Settings \& Population: This analytic cross-sectional study was carried out in the Department of Gynaecology and Obstetrics at Mymensingh Medical College Hospital (MMCH), Mymensingh, Bangladesh from January 2006 to June 2006 for a period of six months. Upon Pregnant women admitted in $\mathrm{MMCH}$ during the above period who were expected to have vaginal delivery and women at term with singleton pregnancy were included as study population. Women with the risk factors for PPH like grand multiparity, multiple pregnancy, IUD, placenta praevia, polyhydramnios, pre-eclampsia, eclampsia, women with previous history of $\mathrm{PPH}$ or coagulation abnormalities or women with caesarean delivery or known case of hypersensitivity to prostaglandin as well as hemoglobin less than $8 \mathrm{gm} / \mathrm{dL}$ were excluded from this study.

Study Procedure: Women were allocated to receive either 10 IU oxytocin intramuscularly or $600 \mu \mathrm{g}$ misoprostol per-rectally by opening a sealed consecutively numbered opaque envelop. Each contained a folded card with one of two sets of instruction. Those marked with "M" indicate randomization to receive $600 \mu \mathrm{g}$ misoprostol per rectally immediately after birth of the baby and clamping and division of the cord. Cards marked with " 0 " indicate randomization to the standard policy of oxytocin. Blood loss during delivery was estimated subjectively by the attending obstetrician. PPH was defined as estimated blood loss more than $500 \mathrm{~mL}$ and severe PPH as estimated blood loss more than $1000 \mathrm{~mL}$. In this study, the hemoglobin estimation was performed by Cyanmethaemoglobin (colorimetric) method. A blood sample for the determination of hemoglobin was obtained from women before delivery and 12 hours after delivery. Blood pressure and temperature before birth and one hour after delivery were recorded. The length of the third stage of labour, need for blood transfusion, use of additional oxytocics were also recorded. In this study, as additional oxytocic agents, intramuscular ergometrine and oxytocin in drip were used. After delivery the occurrence of side effects including nausea, vomiting, diarrhoea, shivering and elevated temperature, raised blood pressure (within one hour after delivery) was recorded.

Statistical Analysis: Analyses were performed with SPSS software, versions 22.0 (IBM SPSS Statistics for Windows, Version 22.0. Armonk, NY: IBM Corp.). Continuous data that were normally distributed were summarized in terms of the mean, standard deviation and number of observations. Categorical or discrete data were summarized in terms of frequency counts and percentages. For end points analysis, Chi-square test or Fisher's exact test was used for categorical variables and an analysis of variance (Student $t$ Test) for continuous outcomes. A two-sided P value of less than 0.05 was considered to indicate statistical significance. Two distinct treatment comparisons were planned in this study. The primary and secondary efficacy analyses were analyzed according to the kind of variables.

\section{Results}

A total number of 100 women were recruited for this study after fulfilling the inclusion and exclusion criteria of which 50 women were in the group A who were treated with misoprostol and the rest of 50 women were in group B who were treated with oxytocin. In this study majority of the patients were belonged to age group 20 to 25 years in both the groups (Table 1).

In oxytocin group $94.0 \%$ of the patients had undergone normal spontaneous vaginal delivery and $6,0 \%$ had instrumental delivery done by ventouse. In misoprostol group, $98.0 \%$ of the patients had undergone normal spontaneous vaginal delivery and $2.0 \%$ had 
instrumental delivery done by ventouse (Table 2 ).

Table 1: Age Incidence of the Patients $(n=100)$

\begin{tabular}{lccc}
\hline Age Group & Group A & Group B & P Value \\
\hline 20 to 25 Years & $32(64.0 \%)$ & $31(62.0 \%)$ & \\
26 to 30 Years & $13(26.0 \%)$ & $12(24.0 \%)$ & \\
31 to 35 Years & $4(8.0 \%)$ & $6(12.0 \%)$ & $>0.05$ \\
36 to 40 Years & $1(2.0 \%)$ & $1(2.0 \%)$ & \\
Total & $\mathbf{5 0 ( 1 0 0 . 0 \% )}$ & $\mathbf{5 0}(\mathbf{1 0 0 . 0 \% )}$ & \\
\hline
\end{tabular}

Chi-square test was performed to see the level of significance; group $\mathrm{A}=$ misoprostol; group $\mathrm{B}=$ oxytocin

Table 2: Mode of delivery among The Study Population $(\mathrm{n}=100)$

\begin{tabular}{lccl}
\hline Mode of Delivery & Group A & Group B & P Value \\
\hline Spontaneous & $49(98.0 \%)$ & $47(94.0 \%)$ & \\
Instrumental & $1(2.0 \%)$ & $3(6.0 \%)$ & $>0.05$ \\
Total & $\mathbf{5 0}(\mathbf{1 0 0 . 0} \%)$ & $\mathbf{5 0}(\mathbf{1 0 0 . 0} \%)$ & \\
\hline
\end{tabular}

Chi-square test was performed to see the level of significance; group $\mathrm{A}=$ misoprostol; group $\mathrm{B}=$ oxytocin

In both the groups, $98 \%$ cases placenta were expelled out spontaneously by active management. Only in $2 \%$ cases manual removal of placenta was done due to retained placenta in both the groups. The differences were statistically not significant (Table 3 ).

Table 3: Mode of Placental Delivery among the Study Population $(\mathrm{n}=100)$

\begin{tabular}{lccc}
\hline Mode of Delivery & Group A & Group B & P Value \\
\hline Spontaneous & $49(98.0 \%)$ & $49(98.0 \%)$ & \\
Manual & $1(2.0 \%)$ & $1(2.0 \%)$ & $>0.05$ \\
Total & $\mathbf{5 0 ( 1 0 0 . 0 \% )}$ & $\mathbf{5 0 ( 1 0 0 . 0 \% )}$ & \\
\hline
\end{tabular}

Chi-square test was performed to see the level of significance; group $\mathrm{A}=$ misoprostol; group $\mathrm{B}=$ oxytocin

In oxytocin group $2.0 \%$ have developed nausea, $4.0 \%$ patients have developed shivering. None have developed vomiting, diarrhoea, temperature. In misoprostol group $10.0 \%$ patients have developed nausea, $18.0 \%$ patients have developed shivering, $4.0 \%$

Table 4: Side Effects among the Study Population $(\mathrm{n}=$ 100)

\begin{tabular}{lccc}
\hline Side effects & Group A & Group B & P Value \\
\hline Nausea & $5(10.0 \%)$ & $1(2.0 \%)$ & $<0.05$ \\
Vomiting & $0(0.0 \%)$ & $0(0.0 \%)$ & $>0.05$ \\
Shivering & $9(18.0 \%)$ & $2(4.0 \%)$ & $<0.05$ \\
Diarrhoea & $0(0.0 \%)$ & $0(0.0 \%)$ & $>0.05$ \\
Temperature & $2(4.0 \%)$ & $0(0.0 \%)$ & $>0.05$ \\
\hline
\end{tabular}

Chi-square test was performed to see the level of significance; group $\mathrm{A}=$ misoprostol; group $\mathrm{B}=$ oxytocin patients have developed rise of temperature, none have developed diarrhoea, vomiting. The differences were statistically significant (Table 4).

In this study $4.0 \%$ patients from oxytocin group and $2.0 \%$ patient from misoprostol group required blood transfusion (Table 5).

Table 5: Blood Transfusion Required Between the Groups $(\mathrm{n}=100)$

\begin{tabular}{lccc}
\hline Group & \multicolumn{2}{c}{ Blood Transfusion } & P Value \\
\cline { 2 - 3 } & Required & Not Required & \\
\hline Group A & $1(2.0 \%)$ & $49(98.0 \%)$ & \\
Group B & $2(4.0 \%)$ & $48(96.0 \%)$ & $>0.05$ \\
Total & $\mathbf{5 0}(\mathbf{1 0 0 . 0} \%)$ & $\mathbf{5 0}(\mathbf{1 0 0 . 0} \%)$ & \\
\hline
\end{tabular}

Chi-square test was performed to see the level of significance; group $\mathrm{A}=$ misoprostol; group $\mathrm{B}=$ oxytocin

\section{Discussion}

Although the incidence of haemorrhage related maternal death in developed countries had declined, post-partum haemorrhage is still a major problem in developing countries like Bangladesh ${ }^{10}$. It is now well established that preventive measures are preferable to interven. The routine use of oxytocin in third stage of labour has been shown to reduce the incidence of PPH. However, there have some potential problem as well as trained personal are needed for their administration.

In this study, rectal administration of misoprostol has been studied as an alternative to oxytocin for the prevention of post-partum haemorrhage in low risk population. Potential advantages of misoprostol includes well tolerated, its stability in light and room temperature, its low cost and easy administration ${ }^{11}$. The purpose is not to replace conventional use of oxytocin but to make misoprostol available in midwives and rurally located physicians for whom parenteral oxytocin seems to be difficult. This suggestion was based on this present observational study. The main outcome measures examined in this study were the efficacy and safety of per rectal administration of misoprostol in prevention of post-partum hemorrhage ${ }^{12}$.

In this present study 100 women were enrolled. Among them 50 women treated with intramuscular oxytocin and are shown as oxytocin group and 50 women treated with rectally administered misoprostol are shown as misoprostol group. Their characteristics are summarized in different tables. In oxytocin group $94 \%$ of the patients had undergone normal spontaneous vaginal delivery and $6.0 \%$ had instrumental delivery done by ventouse. In misoprostol group, $98.0 \%$ of the patients had undergone normal spontaneous vaginal delivery and $2.0 \%$ had 
instrumental delivery done by ventouse. The present comparative study has shown that rectally administered misoprostol is as effective as oxytocin, in terms of minimization of blood loss in the third stage.

About the side effects, shivering and nausea occurred in $18 \%$ and $10 \%$ cases respectively in misoprostol group which is significant. But these side effects are not significant in case of Oxytocin group. In the study shivering occurred in 30\% cases of Misoprostol group which is very significant.

In oxytocin group $2.0 \%$ have developed nausea, $4.0 \%$ patients have developed shivering. None have developed vomiting, diarrhoea, temperature. In misoprostol group $10.0 \%$ patients have developed nausea, $18.0 \%$ patients have developed shivering, $4.0 \%$ patients have developed rise of temperature, none have developed diarrhoea, vomiting. The differences are statistically significant. Shivering is self-limiting and a trend towards elevated temperature and shivering in post-partum period have been noted in misoprostol group ${ }^{13}$. However, shivering may be dose dependent. Further research is needed to understand the relationship of shivering and to identify methods to overcome this side effect. From this present study it can be stated that per rectally administered misoprostol may be effective in the prevention of PPH as an alternative to conventional intramuscular oxytocin ${ }^{14}$. The results of this study suggest but not conclusively that misoprostol may reduce the risk of $\mathrm{PPH}$.

In this study $4.0 \%$ patients from oxytocin group and $2.0 \%$ patient from misoprostol group required blood transfusion. It does not increase blood pressure, has few side effects and well tolerated. Further studies are needed to assess the use of misoprostol in women at risk of post-partum haemorrhage and in the rural setting of developing countries.

There are some limitation of the study. Only patients delivered in the hospital were taken for study. So this does not reflect the overall picture of the country, where most deliveries are conducted by Dais/ TBA at home. The diagnosis of PPH has been mainly clinical and to a little extent investigation depended, as facilities are inadequate in the set up.

\section{Conclusion}

In conclusion less amount of blood loss is found in misoprostol group than oxytocin group. In addition there are less side effects in misoprostol group in comparison with oxytocin group. The mode of delivery is not statistically significantly difference between misoprostol and oxytocin groups. Further large scale study should be conducted to see the real sceneio. Misoprostol may be an alternative to conventional standard intramuscular oxytocin for the prevention of $\mathrm{PPH}$ in low risk women.

\section{References}

1. Say L, Chou D, Gemmill A, Tunçalp Ö, Moller AB, Daniels J, Gülmezoglu AM, Temmerman M, Alkema L. Global causes of maternal death: a WHO systematic analysis. The Lancet global health. 2014;2(6):e323-33

2. Abdel-Aleem H, Singata M, Abdel-Aleem M, Mshweshwe N, Williams X, Hofmeyr GJ. Uterine massage to reduce postpartum hemorrhage after vaginal delivery. International Journal of Gynecology \& Obstetrics 2010;111(1):32-6

3. Salati JA, Leathersich SJ, Williams MJ, Cuthbert A, Tolosa JE. Prophylactic oxytocin for the third stage of labour to prevent postpartum haemorrhage. Cochrane Database of Systematic Reviews. 2019(4).

4. Prendiville W, Elbourne D, Chalmers I. The effects of routine oxytocic administration in the management of the third stage of labour: an overview of the evidence from controlled trials. BJOG: An International Journal of Obstetrics \& Gynaecology 1988;95(1):3-16

5. Adhikari S, Rana A, Bista KD. Active management of third stage of labour: comparison between prophylactic intramuscular methylergometrine and intramuscular oxytocin. Nepal Journal of Obstetrics and Gynaecology 2007;2(2):24-8

6. Ezeama CO, Eleje GU, Ezeama NN, Igwegbe AO, Ikechebelu JI, Ugboaja JO, et al. A comparison of prophylactic intramuscular ergometrine and oxytocin for women in the third stage of labor. International Journal of Gynecology and Obstetrics 2014;124(1):67-71

7. Modi V, Goel JK, Kashyap A, Arya SB, Kar J, Goel R. Active management of third stage of labor: A comparison of various uterotonic. Journal of South Asian Federation of Obstetrics and Gynaecology 2014;6(3):151-5

8. Dickinson JE, Doherty DA. Optimization of third-stage management after second-trimester medical pregnancy termination. American Journal of Obstetrics and Gynecology 2009;201(3):303.e1-7.

9. Jago AA, Ezechi OC, Achinge GI, Okunlola MA. Effect of oxytocics on the blood pressure of normotensive Nigerian parturients. Journal of Maternal-Fetal \& Neonatal Medicine 2007;20(9):703-5

10. Singh G, Radhakrishnan G, Guleria K. Comparison of sublingual misoprostol, intravenous oxytocin, and intravenous methylergometrine in active management of the third stage of labor. International Journal of Gynecology \& Obstetrics 2009;107(2):130-4

11. Dhananjaya BS, Charishma S. Comparative study of efficacy and safety of intramuscular oxytocin with intramuscular methylergometrine in the active management of third stage of labour. Research Journal of Pharmaceutical, Biological and Chemical Sciences 2014;5(3):734-9

12. Boopathi A, Nayak SR, Rao A, Rao B. Oxytocin versus methylergometrine in the active management of third stage of labour. Open Journal of Obstetrics and Gynecology 2014;4:666-71 13. Orji E, Agwu F, Loto O, Olaleye O. A randomized comparative study of prophylactic oxytocin versus ergometrine in the third stage of labor. International Journal of Gynecology \& Obstetrics 2008;101(2):129-32

14. Saito K, Haruki A, Ishikawa H, Takahashi T, Nagase H, Koyama $\mathrm{M}$, et al. Prospective study of intramuscular ergometrine compared with intramuscular oxytocin for prevention of postpartum hemorrhage. Journal of Obstetrics and Gynaecology Research 2007;33(3):254-8 